\title{
A Study of Sports Hospitality at the Rugby World Cup 2019 for a Tourism Experience Product: A Consideration from the Viewpoint of Eliminating Overtourism in Spectator Sports
}

\author{
Masamichi Aihara \\ Faculty of Human Sciences, Osaka University of Economics, 2-2-8 Osumi, Higashiyodogawa-ku, Osaka 533-8533, Japan
}

\begin{abstract}
In this research project, we focus on sports hospitality at the Rugby World Cup 2019 as a practical example of the qualitative pursuit of sports tourism in the Japanese tourism industry. STH Japan K.K., Japan's first company specializing in sports hospitality, hosted the first mega sports event held in Japan. A similar spectator service will next be implemented at the Tokyo Olympics and Paralympics. Sports hospitality is a new way to enjoy watching sports by adding a meal and entertainment before and after the match to the event ticket. Positioning and using sports hospitality as a tourism experience product, we can use qualitatively designed creative and effective methods that professional human resources could provide to tourists. This research project provides an overview of tourism experience products, looks at their economic effects at the Rugby World Cup 2019, and the sales results of the sports hospitality at the event. I conducted an observation survey at the Rugby World Cup 2019 Scotland vs. Samoa match held at Misaki Park Stadium (Kobe, Hyogo) on September 30, 2019 focusing only on tourism products in that framework. I also conducted a qualitative survey on March 18, 2020 in a semi-structured interview format with STH Japan K.K. senior advisors. The research results revealed the possibility of eliminating overtourism in spectator sports and the lack of sports hospitality spaces in Japan. Usually, when watching a sports match where many spectators gather, the uniform start and end times cause crowding and overtourism. The conventional challenge has been to create tourism products that reduce congestion and provide an enjoyable tourism experience. Sports hospitality is effective for relieving the stress caused by overtourism in spectator sports. In order to solve the shortage of sports hospitality spaces, one issue to consider is the deregulation by the government.
\end{abstract}

Key word: Sports tourism, sports hospitality, overtourism, Rugby World Cup 2019, tourism product.

\section{Introduction}

The 2019 Rugby World Cup was held for 44 days from September 20 to November 2. The Japanese national team advanced to the top eight and people were enthusiastic about the event. In addition, it attracted people from countries outside of Japan, including from countries in Europe, America, and Oceania, and approximately 400,000 tourists visited Japan during that time. The consumption per spectator reached 2.4 times [1] that of other tourists visiting

Corresponding author: Masamichi Aihara, professor, Research fields: sports management, sports business and Olympics.
Japan. It was a very good outcome for Japan, which aims to become a tourism-oriented country.

Previously, the number of foreign visitors to Japan had increased five-fold in the seven years until 2018, but the concentration of tourists coming from certain countries and regions was noticeable. In 2018, approximately 31.19 million visitors came to Japan. Of these, 3/4 were visitors from East Asia (China, South Korea, Taiwan, Hong Kong). However, in 2019, Korea's relationship with Japan deteriorated, and the number of visitors to Japan in October 2019 decreased by $65.5 \%$ from the same month of the previous year and decreased by $65.1 \%$ in November, impacting Oita and other cities. In addition, consumption amounts per 

Consideration from the Viewpoint of Eliminating Overtourism in Spectator Sports

Chinese visitor seemed to have reached a peak. 2019 was a year in which the perceived danger of spending in Japan on East Asian demand [1].

The government has set a goal of increasing the number of annual visitors to Japan to 60 million by 2030 after the Tokyo Olympics and Paralympics, which were postponed to 2021, and the 2025 International World Expo (Osaka). In order to maintain the momentum of inbound tourists and their consumption, it is indispensable to attract tourists from countries other than East Asia and appeal to consumers in Japan.

Japanese tourists from the Tokyo metropolitan area continue to concentrate their visits in specific areas of the Kansai region and "tourism pollution" that hinders the lives of residents in Asakusa (Tokyo), Kamakura City (Kanagawa Prefecture), and Kyoto City cannot be ignored. The World Tourism Organization (UNWTO) refers to overtourism as "the impact of tourism on all or part of a destination, apparently excessively and negatively affecting the quality of life of citizens or the experience of visitors" [2].

Japan has grown into a major tourism power in a short period of time, but an excessive quantitative expansion of the tourism industry has had more negative impacts than positive impacts. The tourism industry, which has developed rapidly in a mature economy, is about to turn.

Therefore, it is an urgent task for the Japanese tourism industry to shift from quantitative to qualitative pursuits in the future. In this research, with a focus on a Japanese tourism industry that is shifting from quantitative to qualitative pursuits, we will discuss eliminating overtourism in spectator sports by using sports hospitality at the Rugby World Cup 2019 as an example.

\section{Purpose of Research}

In this research, as a practical example of a qualitative pursuit of sports tourism in the Japanese tourism industry, the focus will be the sports hospitality services at the Rugby World Cup 2019. Sports hospitality is a new way to enjoy watching sports by adding a meal and entertainment before and after the match to a spectator's ticket. STH Japan K.K. was established on February 1, 2017 as Japan's first specialized sports hospitality company, and provided the first official sports hospitality service at a mega sports event held in Japan. In viewing sports hospitality as an experiential tourism product, we analyze the qualitatively designed creative and effective methods that professional human resources can provide to tourists.

\section{Research Method Framework}

Inoue [3] used Schumpeter's innovation theory and classification to present a framework of strategic innovation in tourism experiences by adding the characteristics of tourism innovation. Focusing only on the tourist products in Inoue's framework [3], my research began with the kick off at 19:15 on September 30, 2019 at Misaki Park Stadium in Kobe City, Hyogo Prefecture. I observed by participating in sports hospitality at the Scotland vs. Samoa match of the Rugby World Cup 2019. I also conducted a qualitative survey in a semi-structured interview format with Mr. Kurata Tomoki, Senior Advisor of STH Japan K.K. on March 18, 2020. I will analyze the tourism experience products at the Rugby World Cup from the viewpoint of the STH Japan K.K. office (Shinjuku, Tokyo), the elimination of overtourism in spectator sports, and the lack of sports hospitality space, and then will summarize the results.

\section{Review of Previous Studies}

\subsection{Sports Hospitality as Tourism Products}

Holbrook and Hirschman [4] were the first researchers to elaborate on the differences in pleasure experiences and physical utility when consuming goods. Pine and Gilmore [5] later pointed out that "a company can add value by including experience in goods and services through entertainment". Value 


\section{A Study of Sports Hospitality at the Rugby World Cup 2019 for a Tourism Experience Product: A Consideration from the Viewpoint of Eliminating Overtourism in Spectator Sports}

creation has shifted from focusing on the production and sale of physical value to experience value through solution value and service value [6]. Recently, the trend of pursuing entertainment experiences which is the so-called "experience economy" has become remarkable in the tourism industry [3]. Tourists seek newness, learning, belonging, hedonism, transformation, personal branding, and identity.

Jensen [7] describes these characteristics of society as a "dream society". The goods/services themselves are recognized as hotels, restaurants, entertainment companies, car rental companies, tourist guides, etc. Tourism companies do not simply provide products and services, but produce products that embody intangible features. For example, the lifestyle and culture of local residents can be incorporated into products and services to provide a satisfying tourist experience for visitors. In addition to the experience economy, the tourism industry is often discussed from multiple perspectives that overlap, such as experience design [8] and experience marketing [9], which complicates the innovation process.

Inoue [3] uses Schumpeter's innovation theory and classification to present a framework for strategic innovation in experience-based tourism, taking into account the characteristics of tourism innovation. In order for tourist companies to secure a competitive advantage, one strategic issue is how to provide tourist experiences that tourists seek, in order to enhance customer value. To that end, it is essential to innovate from the four aspects of tourism: products (Product), tourism marketing (Promotion), tourism production process (Process), and tourism policy (Policy).

In particular, tourism products are often packages constructed from a series of services provided by multiple companies. Therefore, it may be difficult to understand what is new. Even if the sub-service provided by each company is not new, the package is often new and innovative for the market. Therefore, Weiermair [10] defines tourism products as "experiences". Experience-based tourism products include tangible and intangible elements [3]. Tourism products can be divided into physically tangible products and intangible services, but in many cases, they will only become products when they are combined. To meet these demands, Inoue [3] points out.

Therefore, to be a tourist product, the sports hospitality industry needs to analyze creative and effective methods to qualitatively design experiences that professional human resources can provide to tourists.

\subsection{Economic Benefits of Rugby World Cup 2019}

Up to now, all eight Rugby World Cups have been held in Europe and other traditional rugby countries and regions in the Southern Hemisphere. The World Cup in Japan, which was the first time a World Cup was held in Asia, had 45 hot games in 44 days at 12 venues nationwide. It was unfolded. The Rugby World Cup 2019 organizing committee announced that it had mobilized a total of $1,740,000$ spectators. At first, there were some who were worried about the mobilization of the audience to the tournament in Japan, but when ticket sales began, the response was favorable. Eventually, about 1.84 million sheets, which is equivalent to about $99 \%$ of the available seats, were sold, and the highest sales rate of tickets to any World Cup was recorded.

Fans also packed "Fan Zones" in 16 locations nationwide where large screens were used to broadcast games, and housed approximately 1,137,000 visitors during the tournament to set a new World Cup record. Although there were no major disruptions to the transportation of spectators, three games in Yokohama and other cities were canceled due to the impact of Typhoon No. 19, which caused enormous damage mainly in eastern Japan. However, the head of the international governing body, World Rugby Chairman Bill Beaumont, gave high praise for the tournament saying "it was memorable as the greatest World Cup. Japan was the best host country.'[11] 

Consideration from the Viewpoint of Eliminating Overtourism in Spectator Sports

According to the Japan National Tourism Organization (JNTO), the number of inbound tourists from participating countries, mainly rugby powerhouses, increased in September and October 2019. The tourists from the UK, increased by about 50,000 compared to the same period last year, and from the United States, the increase was about 30,000. New Zealand, Australia, Ireland, and France each had more than 10,000 people attended. Hosting this tournament enabled a significant increase in tourism from countries other than East Asia, which is the mainstay of visitors to Japan [12].

The consumption amount per visitor to Japan was also large. According to the JNTO, the average expenditure per spectator was 385,000 yen, more than double the average of 159,000 yen for non-spectators. The average number of nights stay was 13.3 nights, which is longer than the 8.2 nights for non-spectators, and the expenditure per night was nearly 50\% higher. Looking closely at the spending of spectators from the four countries of Britain, France, the United States, and Australia, the accommodation, food, transportation, spectator, and liquor costs in all countries exceeded $90 \%$ in total. In particular, according to Kirin Brewery, which manufactures and sells beer from the tournament sponsor Heineken (Netherlands) in Japan, the sales volume of Heineken from September to October 2019 was approximately three times that of the same period of the previous year [13]. Originally, visitors from these four countries spent a lot of money per person, including expenditures on accommodations, food, and drink. This is in contrast to Chinese tourists who spent about half of these amounts.

\subsection{Sports Hospitality Sales Results at Rugby World Cup 2019}

STH Japan K.K. sold a Sports Hospitality Plan, which combined spectator tickets for Japan's first Rugby World Cup with meals and shows. According to Kurata (STH Japan K.K.), "64,000 copies were sold during the Rugby World Cup, and total sales were over 10 billion yen. In terms of sales results, the ratio between overseas and domestic was 3:7. However, the sales amount per account was larger for overseas sales. Sales are at a ratio of 5:5, so visitors are buying high-priced products. The sales by region is larger Tokyo and Yokohama than other venues" (Kurata, STH Japan K.K.).

Excluding sales of Premier seats, the sales channels were direct sales, agency sales, and the Internet. The majority were direct sales and agency sales. The prices were JPY 115,000 to JPY 43,856,000 per person, which is high compared to other types of entertainment (Table 1).

According to a survey by JTB and Deloitte, the domestic market for sports hospitality tourism experience products is potentially small at 32.5 billion yen. Professional baseball and sumo wrestling are conspicuous. However, VIP tourist products are offered for professional basketball and American football games in the United States, and in Europe, for the Wimbledon tournament, the European soccer league, etc. It has been established that the larger the sporting event is on a global scale, the more visitors are attracted from Japan and overseas, and the greater the economic effect. The global market for sports hospitality is estimated to be a trillion yen ${ }^{5}$.

\section{Considerations}

\subsection{Tourism Experience Products in Sports Hospitality}

In terms of experience-based tourism products, sports hospitality is an expensive sports game combined with food, drinks, and shows. We will discuss qualitatively designed, creative, and effective methods for sports hospitality tourism experience products that professional personnel can provide for visitors. We will analyze the following topics: tourism experience products at the Rugby World Cup, the elimination of overtourism in spectator sports, and the lack of sports hospitality spaces.

\footnotetext{
${ }^{5}$ Nihon Keizai Shimbun Evenig, 1, 2019.11.2.
} 
Table 1 Sports hospitality price list for Rugby World Cup 2019.

\begin{tabular}{|c|c|c|c|}
\hline Sports hospitality type & Venue & Meal & Price (unit: $¥$ ) \\
\hline $\begin{array}{l}\text { Private Suite in Temporary Structure } \\
\text { outside Stadium }\end{array}$ & Yokohama & $\begin{array}{l}\text { Private room } \\
\text { (over } 20 \text { people) }\end{array}$ & $43,856,000$ \\
\hline $\begin{array}{l}\text { Function Room Style in Temporary } \\
\text { Structure outside Stadium }\end{array}$ & Yokohama & Restaurant Venue & $180,000 \sim 367,500$ \\
\hline Lounge Area in Stadium & $\begin{array}{l}\text { Sapporo, Kumagaya, Tokyo, } \\
\text { Shizuoka, Toyota, Kobe, } \\
\text { Fukuoka, Oita, Kumamoto. }\end{array}$ & Restaurant Venue & $115,000 \sim 240,000$ \\
\hline $\begin{array}{l}\text { Existing Function room close to Stadium } \\
\text { on match day }\end{array}$ & Tokyo, Yokohama, Kamaishi & Restaurant Venue & $200,000 \sim 260,000$ \\
\hline $\begin{array}{l}\text { Existing Function room close to Stadium } \\
\text { on previous day }\end{array}$ & $\begin{array}{l}\text { All Venues } \\
\text { (exclude Kamaishi) }\end{array}$ & Restaurant Venue & $140,000 \sim 250,000$ \\
\hline
\end{tabular}

Resource: STH Japan K.K.

\subsection{Tourism Experience Products at the Rugby World Cup}

Tourism experience products at the Rugby World Cup were organized with tangible products and intangible services. Tangible goods are concrete in nature and include landscapes, theme parks, buildings, ruins, museums, and souvenirs. The tangible tourist products related to the Rugby World Cup were not only watching games, but also meals and services at restaurants. Information was provided via a web page dedicated to each customer, and services included tickets with customer's names, talk shows, souvenirs (original programs and original notebooks at Kobe venues), entry/exit via dedicated lanes that did not have lines, and were escorted to seats.

Intangible services included the development of new services, the introduction of new production/delivery processes, the creation of new forms of organization, and the introduction of new technologies [14]. The STH organization was established to provide intangible tourist products for the Rugby World Cup. Space setup and production (deployment of temporary facilities such as tents) is said to be a creative and effective way to add innovation to professional "experience design" and involve tourists in the designed experience.

\subsection{Resolving Overtourism in Watching Sports Games}

Initially, the Hanazono Rugby Stadium, located in
Higashi-Osaka City, Osaka Prefecture, was the subject of the survey, but the Platinum package was not sold for this venue. Therefore, we surveyed Misaki Park Stadium (Kobe City, Hyogo Prefecture), which provided the only Rugby World Cup 2019 Platinum package at a Kansai region venue. We conducted an observational survey of the official hospitality program at the Scotland vs. Samoa match at Misaki Park Stadium, held at 19:15 on September 30, 2019 (Fig. 1). The Platinum package began $2 \mathrm{~h}$ before the match. Participants entered the restaurant venue where several large monitors and a stage were installed in a spacious space overlooking the entire pitch. Customers enjoyed a unique space designed for the Rugby World Cup 2019. More than 70\% of the customers in the venue were Scottish and the rest were Japanese. No Samoans were present. Despite the fact that this event was held in Japan, the number of Japanese attendees was small, so it was possible to deduce that this service was not well established in Japan.

We began with a welcome drink service at the restaurant and then we sat down and had a meal. Normally I would have to wait in line to buy stadium food, but here I was able to sit back and enjoy the food and drinks supervised by a chef at a table with a tablecloth. After that, there was entertainment that explained the highlights of the game by famous past players. 


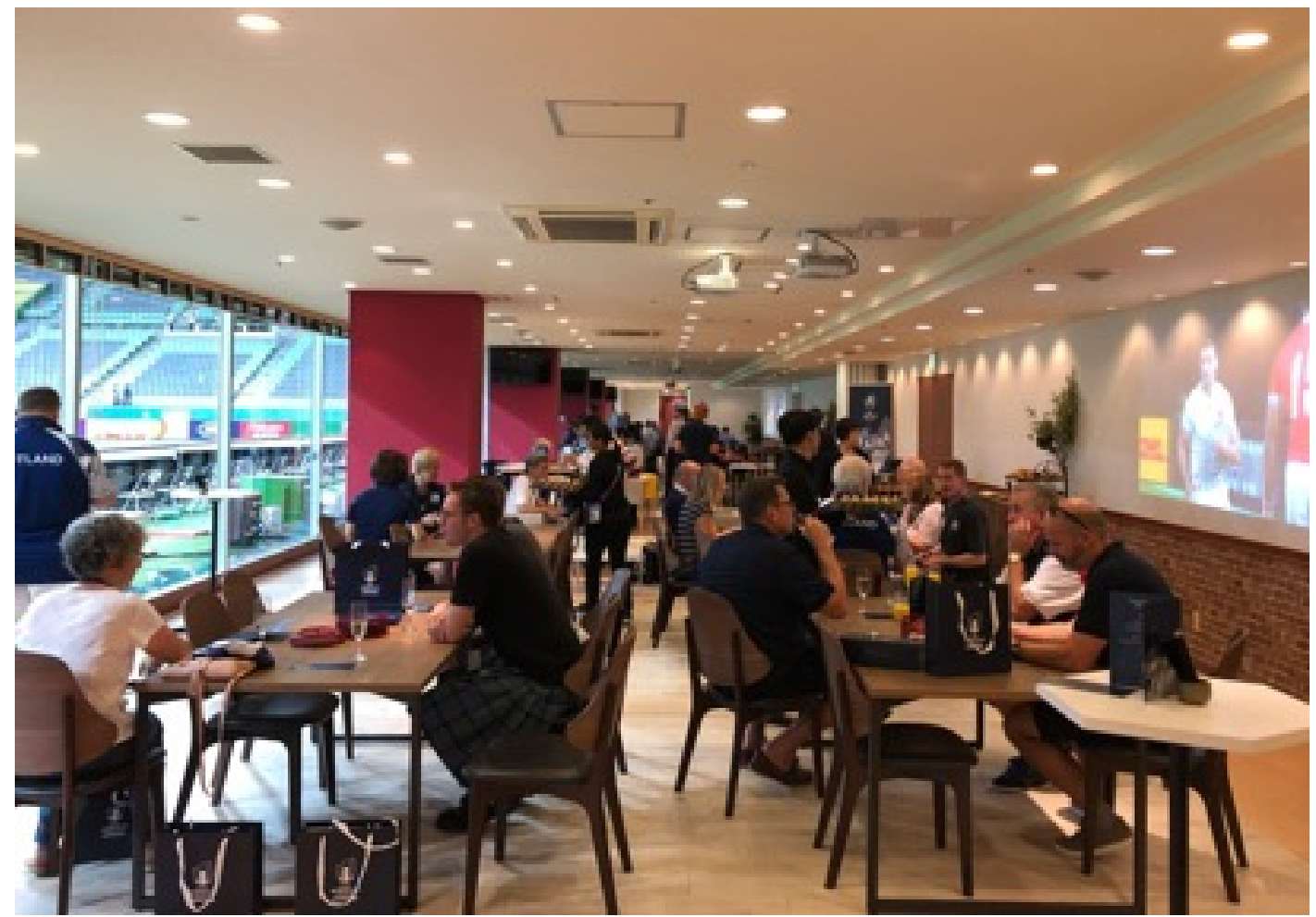

Fig. 1 Restaurant venue in Misaki Park Stadium.

When I left the restaurant 20 min before kick-off, I was given a can of beer from the sponsor beer company, and I was escorted to my seat. We watched the match from seats in the middle section of the venue. After the match there was a snack (finger food) and drink service at the restaurant venue. We changed the match while watching the digest video of the match.

As a tourism experience product, sports hospitality can eliminate overtourism for spectator sports. Normally, when watching a sports game where many spectators gather, a game's fixed start and end times cause crowding. Inevitably overtourism occurs. There are many people who are uncomfortable when they return home because of the congestion. If that hinders the next spectator, it has been a challenge to create tourist products that reduce congestion and provide a smooth sightseeing experience. Sports hospitality is a qualitatively designed, creative and effective method that is effective in relieving the stress caused by overtourism.
Also, since tickets can be secured in advance, it is possible for tourists to make plans. Since the information was provided on the customer-only website before the event, there was a page that responded to requests such as vegetarian meals and dress codes. Without a package, it would take time to buy food at the venue shop, but I was able to eat at the restaurant while watching the entertainment. It would be even better if there was a service that could arrange for taxi service for the return trip home.

\subsection{Lack of Sports Hospitality Space at Japanese} Match Venues

"Not only the guest-friendly space, but also the back space such as the kitchen and the private toilet, and the physical space necessary for running the sports hospitality such as the VIP conductor and the catering service route are insufficient", says Kurata (STH Japan K.K.). Intangible services may be provided by luxury hotels that hold large parties, but tangible facility development must be incorporated 


\section{A Study of Sports Hospitality at the Rugby World Cup 2019 for a Tourism Experience Product: A Consideration from the Viewpoint of Eliminating Overtourism in Spectator Sports}

from the initial design stage. Although it is desirable to consider sports hospitality areas during the design stage, public stadiums are reluctant to invest in such spaces due to the financial difficulties of the local government. In order to expand sports hospitality in Japan, which is an expensive service related to sports, the public and private sectors will need to work together. It is necessary to maintain the saucer. Another alternative would be to use a function room (tangible facility) within a hotel, which takes about 30 min to move.

Also, although it is not a sports hospitality space, it raises the vulnerability of the goods store. In Japan, temporary construction conjures an image of a prefabricated hut used at a construction site. It is hoped that the laws and regulations will be relaxed in relation to the establishment of sports hospitality venues in Japan, including related Japanese merchandise stores, by imitating overseas temporary sales spaces with air conditioning.

\section{Results}

In this study, as a practical example of the qualitative pursuit of sports tourism in Japan's tourism industry, professional staff will provide tourists with sports hospitality, like the tourism experience product at the Rugby World Cup 2019. I have considered qualitatively designed creative and effective methods. As a result of participating in an observational survey of sports hospitality at the Rugby World Cup 2019 and a qualitative survey of STH Japan K.K. senior advisors, we explained that sports hospitality is a tourist experience product and that it could eliminate overtourism in spectator sports. We also pointed out the lack of sports hospitality spaces in Japan.

One of the characteristics of tourism experience products is that they must be produced at the same speed as consumption in order to respond swiftly to changes in tourist preferences. The development of plans and experiences for new tourists is endless, but constant innovation can add new perceptual effects and transform them into competitive tourism products. In order to resolve the lack of sports hospitality spaces, deregulation by the government is required.

The game of rugby has a heavy physical burden on the players, and each team has a long game interval of about one week, so the spectators have time to do other things between games. The game venues are scattered all over the place, and foreigners can enjoy sightseeing and the local food in various places. This was a good opportunity to promote hot springs and tourist attractions around the country by welcoming tourists from rugby powerhouses and taking advantage of the increased awareness of the city to continuously attract visitors.

STH Japan K.K. provided the first official hospitality spectator experience at a mega sports event held in Japan, but a similar spectator service will be implemented at the Tokyo Olympics and Paralympics. 2019 , the first year of peace, was also the first year of sports hospitality in Japan. Although the venues will not be as scattered throughout the country as they were during the Rugby World Cup, the Tokyo Olympic and Paralympic Games and the Osaka World Exposition have the power to attract more diverse people from around the world.

It is difficult to expect sustainable, profitable growth in the Japanese tourism industry without switching from quantitative to qualitative pursuits. In the future, it will be necessary for various players, including new entrants, to build concrete management strategies for discussing major directions and present guidelines for implementing them. The Japanese government should implement policies as an opportunity to leap into a tourism-oriented country. Is it an opportunity to fly to a tourism nation? Japan is at an important crossroads.

Inoue's experience-based framework for strategic innovation in tourism, focused only on tourism products at the Rugby World Cup. Therefore, it is necessary to consider the other three issues from the four aspects of tourism: [3] marketing (Promotion), 

Consideration from the Viewpoint of Eliminating Overtourism in Spectator Sports

tourism production process (Process), and tourism policy (Policy).

\section{Acknowledgements}

This work was supported by JSPS KAKENHI Grant Number JP19K12568 and was supported by the 2019 Joint Research Fund from Osaka University of Economics.

\section{References}

[1] Nihon Keizai Shimbun Daily,3, 2019.12.30.

[2] World Tourism Organization (UNWTO), Centre of Expertise Leisure, Tourism \& Hospitality, NHTV Breda University of Applied Sciences, and NHL Stenden University of Applied Sciences. 2019. “'Overtourism'? - Understanding and Managing Urban Tourism Growth beyond Perceptions." Executive Summary Japanese version, UNWTO, Madrid. doi: https://doi.org/10.18111/9789284420667.

[3] Ikegami, J., and Waseda. 2019. Inbound Business Strategy Study Group 2019. Nikkei Publishing Inc., 94-100

[4] Holbrook, M., and Hirschman, E. 1982. "The Experiential Aspects of Consumption: Consumer
Fantasies, Feelings, and Fun." Journal of Consumer Research 9 (2): 132-40.

[5] Pine, J., and Glimore, J. 1999. The Experience Economy. Harvard Business Press.

[6] Gustafsson, A., Nilsson, L., and Johnson, M. 2003. "The Role of Quality Practices in Service Organizations." International Journal of Service Industry Management 14 (2): 232-44.

[7] Jensen, R. 1999. The Dream Society: How the Coming Shift Information to Imagination Will Transform Your Business. Copenhagen, Denmark: Jyllandspostens Frolag.

[8] Jantzen, C., Ventner, M., and Bouchet, J. 2011. Experience Design. Fredriksberg: Samfundslitteratue.

[9] Mossberg, L. 2007. "A Marketing Approach to the Tourist Experience." Journal Scandinavian Journal of Hospitality and Tourism 7: 59-74.

[10] Weiermair, K. 2006. "Prospects for Innovation in Tourism: Analyzing the Innovation Potential throughout the Tourism Value Chain." Journal of Quality Assurance in Hospitality \& Tourism 6: 59-72.

[11] Nihon Keizai Shimbun Daily.32. 2019.11.4

[12] Nihon Keizai Shimbun Daily,3. 2019.11.3,

[13] Nihon Keizai Shimbun Evenig, 1, 2019.11.2.

[14] Gronroos, C. 1990. "Service Management: A Management Focus for Service Competition." International Journal of Service Industry Management 1 (1): 6-14. 